\title{
The role of uncertainty in the transmission of monetary policy effects on bank lending
}

\author{
Christopher F. Baum* \\ Department of Economics, Boston College \& DIW Berlin \\ Mustafa Caglayan \\ Department of Economics, University of Sheffield \\ Neslihan Ozkan \\ Department of Economics, University of Bristol
}

April 20, 2008

\begin{abstract}
In this paper we re-examine commercial banks' lending behavior taking into account changes in the stance of monetary policy in conjunction with changes in financial sector uncertainty. Using a very large data set covering all banks in the US between 1986-2000, we show that financial uncertainty has an important and significant role in the monetary policy transmission mechanism that varies across bank categories and the strength of banks' balance sheets. While there is some evidence of a bank lending channel for total loans, there is no evidence of such a channel for commercial and industrial loans in our extended model.
\end{abstract}

Keywords: monetary transmission mechanism, bank lending, financial uncertainty, bank lending channel

JEL: E44, E52, G32.

\footnotetext{
${ }^{*}$ We are grateful to Ben S. Bernanke for providing us with his data and programs, Oleksandr Talavera for excellent research assistance, and give thanks to seminar participants at the University of Leicester and participants of the 2003 York Annual Econometrics Conference, the 2004 meetings of the European Economic Association, the 2004 meetings of the Money, Macro and Finance Research Group and 2004 Kent Macroeconomics Workshop for their useful comments. We are grateful to an anonymous reviewer for their constructive suggestions. The standard disclaimer applies. Corresponding author: Christopher F. Baum, Department of Economics, Boston College, Chestnut Hill, MA 02467 USA, Tel: 1+617-552-3673, fax 1+617-552-2308, e-mail: baum@bc.edu.
} 


\section{Introduction}

Understanding the role of commercial banks in the transmission mechanism of monetary policy is essential in explaining the effects of a policy change on the aggregate economy. In seeking to evaluate the effects of monetary policy, research using bank- and firm-level data has unearthed considerable evidence that the impact of changes in monetary policy go beyond the simple textbook interest rate channel. In particular, Kashyap and Stein (2000) (hereafter KS) used the Federal Reserve System's Commercial Bank and Bank Holding Company database to study the impact of monetary policy on bank lending behavior for banks with differing degrees of liquidity, focusing on the period between 1976-1993. KS have shown that smaller and less liquid banks would reduce their loan supply in response to contractionary monetary policy as their ability to raise reservable forms of financing is compromised. As KS point out, another reason for small banks' curtailment of loans is that these banks cannot sell non-reservable liabilities due to a failure of the Modigliani-Miller proposition. These changes in bank lending behavior, particularly affecting bank-dependent borrowers, have important implications for firms' financing behavior as their impact compounds the effects of changes in interest rates.

In this paper, we argue that banks' lending decisions depend not only on the stance of monetary policy but will generally be affected by the prevailing level of uncertainty in the financial sector. The intuition underlying our reasoning is that profit-maximizing banks will make decisions to extend loans to present or potential customers based on the current stance of monetary policy as well as on the level of uncertainty in the financial sector, over and above the constraints posed by regulatory authorities and borrowers' creditworthiness. ${ }^{1}$ In that sense, Kashyap and Stein's model - as well as other models in this strand of literature that investigate the transmission mechanism of monetary policy without taking uncertainty into account-could be misspecified. Such models could lead to biased conclusions due to the exclusion of relevant explanatory variables. Hence, we investigate the impact of

\footnotetext{
${ }^{1}$ Use of the term uncertainty henceforth implies financial sector uncertainty.
} 
changes in monetary policy on bank lending behavior by incorporating financial sector uncertainty into the KS framework. In our extended model, we also include several bank-specific variables which gauge bank capitalization, excess capital and access to internal capital markets.

To achieve our goal, following KS' strategy, we use the Federal Reserve System's Commercial Bank and Bank Holding Company (henceforth BHC) database which contains information on all commercial banks regulated by the Federal Reserve System, the Federal Deposit Insurance Corporation and the Office of the Comptroller of the Currency. Our extract of this data set covers essentially all banks in the U.S. on a quarterly basis from 1986-2000, with over 15,000 observations per quarter in 1986, falling to 8,956 in 2000Q4.

Our analysis proceeds as follows. After carefully constructing variables as suggested in KS to eliminate potential definitional discrepancies, we reestimate the KS model to see if the use of a more recent sample period qualitatively alters their findings. We then focus on the impact of uncertainty on bank lending behavior by employing the return on one-year and five-year Treasury notes as well as the ten-year versus one-year Treasury term spread to generate uncertainty measures from daily data using a method originally proposed by Merton (1980). Using these measures of financial sector uncertainty, we test whether uncertainty as well as the stance of monetary policy have significant effects on the lending behavior of small, medium and large banks with varying degrees of balance sheet strength.

Our findings can be summarized thusly. We first show that the degree of uncertainty has significant effects on bank lending behavior not only on its own (the primary effect) but also through its interaction with the strength of banks' balance sheets (the secondary effect) and through the stance of monetary policy as well as movements in output. Considering all four possible channels simultaneously, as uncertainty increases, we observe that banks holding more liquid assets alter their lending by a smaller amount (and may curtail their lending) relative to those banks which are less liquid. This may reflect the more-liquid banks' concerns for a prudent response in more turbulent times. Those banks already have exhibited a lesser appetite for risky assets, and their response may reflect those preferences. Overall, larger banks tend to alter their lending (up or down) more than their smaller coun- 
terparts during times of heightened uncertainty. This observation is also sensible as one could expect that larger banks would have better and more sophisticated risk management strategies than their smaller counterparts, supporting a more vigorous response.

Our second observation questions the existence of a bank lending channel. Although there is some support for the presence of a bank lending channel when total loans are considered, we find none for commercial and industrial (C\&I) loans. In the light of Kashyap and Stein's (2000) emphasis on C\&I loan results, it would appear that KS-type models are misspecified and deliver biased results. Hence, we conclude that there is generally little support for a bank lending channel in the US.

The rest of the paper is constructed as follows. Section 2 provides a brief survey of the literature discussing the bank lending channel. Section 3 presents the modeling framework and discusses the methodology we employ in our investigation. Section 4 documents our empirical findings, while Section 5 concludes and draws implications for future research.

\section{The bank lending channel}

There is a substantial body of theoretical and empirical literature indicating that monetary policy affects the economy beyond the well known interest rate channel. The intuition for the primary impact of monetary policy via the interest rate channel is that contractionary monetary policy leads to an increase in real interest rates, causing postponement of consumption and a reduction of investment spending. However, as Bernanke and Gertler (1995) point out, the impact of monetary policy on the economy is larger than that implied by the estimates of the interest elasticities of consumption and investment and they suggest that there must be other mechanisms at work. One possibility is that, because contractionary monetary policy decreases the core deposit funding of bank loans through reserve requirements, some banks would reduce their lending activity, as they may be unable to raise nonreservable funds to continue lending due to a failure of the ModiglianiMiller proposition. This view is termed the narrow credit channel or the bank lending channel. 
An earlier study by Bernanke and Blinder (1992) finds that contractionary monetary policy leads to a decline in bank lending activity. Though consistent with the lending view, this study is criticized on the grounds that the use of aggregate data may confound a reduction in the supply of loans with reduced loan demand. Subsequently, Kashyap, Stein and Wilcox (1993; 1996) show that a monetary contraction increases the issuance of commercial paper. This evidence suggests that any reduction in observed lending is not due to a reduction in loan demand, but rather reflects a reduction in loan supply. ${ }^{2}$ Also, Calomiris, Himmelberg and Wachtel (1995) show that during periods of monetary contraction, commercial paper-issuing firms increase trade credit extended by these firms, suggesting that larger firms take up some of the slack created as their smaller customers lose access to bank loans. Along similar lines, Nielsen (2002) concentrates on the use of trade credit by small firms (which is available to all customers, but at penalty rates) and shows that small firms use trade credit more heavily during periods of monetary contraction, supporting the evidence of a bank lending channel.

Turning to studies on bank lending behavior, Peek and Rosengren (1995) and Stein (1998) point out that poorly capitalized banks and those that carry bad loans on their books will suffer reduced access to markets for uninsured funding, and their lending behavior will be more sensitive to monetary shocks. Kishan and Opiela (2000) show that bank size and bank capital affect the ability to raise funds and maintain loan growth during periods of contractionary policy. A more influential study conducted by Kashyap and Stein (2000) employed the BHC database to find that the impact of monetary policy on bank lending activity is stronger, in particular, for small banks with less liquid balance sheets. Similarly, utilizing the approach developed by KS, researchers using European bank-level data have also begun to provide evidence in support of the bank lending channel. For example, Ehrmann, Gambacorta, Martinez-Pags, Sevestre and Worms (2003) use

\footnotetext{
${ }^{2}$ Gertler and Gilchrist (1994) show that large firms' bank borrowing actually increases, while small firms suffer from reductions in the growth rate of bank loans outstanding. Therefore, it could also be that a reduction in bank loans to small firms is driven by a lower demand for credit.
} 
European macroeconomic and bank-level data to determine that banks' response to monetary policy depends crucially on their liquidity.

\section{The bank lending channel under uncertainty}

In this study we aim to broaden our understanding of banks' lending behavior considering changes in the stance of monetary policy in conjunction with variations in financial sector uncertainty by extending the basic KS model. Mainly, we focus on the effects of uncertainty that emanates from Federal Reserve actions and present evidence on the role of variations in short and long term interest rates as well as a term spread. Overall, our goal is to investigate the sensitivity of banks' lending behavior to measures of uncertainty that capture the state of the financial environment.

Surprisingly, although the existing literature contains a variety of evidence in support of the bank lending channel, it has not considered the impact of uncertainty on bank lending behavior. In the absence of uncertainty, it would be sufficient to investigate the role of key indicators of macroeconomic performance to understand the behavior of economic agents. More realistically, one must be concerned with second moments (uncertainty about the course of the macroeconomy, the volatility of interest rates, or more generally financial sector volatility) along with the first moments. These second-moment effects may be of key relevance to economic policymakers as they may have a sizable influence on commercial banks' decision-making process. Therefore, it is crucial to evaluate the degree to which financial sector uncertainty will affect banks' willingness to utilize available loanable funds. In our study, we seek to demonstrate that uncertainty has important effects on bank lending behavior, and that a model of the transmission mechanism of monetary policy which ignores the primary and secondary effects of uncertainty could be misspecified in their absence. ${ }^{3}$

KS follow two different approaches, labelled as the two-step model and the one-step model. Since they find that the two-step approach "probably errs on the side of being overparameterized" (2000, p. 421), we particularly

\footnotetext{
${ }^{3}$ The models employed in many of the bank-level empirical studies that have followed in KS' footsteps are subject to the same criticism.
} 
focus on their one-step bivariate approach which takes the following form:

$$
\begin{aligned}
\Delta \log \left(L_{i t}\right)= & \sum_{j=1}^{4} \alpha_{j} \Delta \log \left(L_{i t-j}\right)+\sum_{j=0}^{4} \mu_{j} \Delta M_{t-j}+\sum_{j=0}^{4} \pi_{j} \Delta G D P_{t-j}+ \\
& \Theta T I M E_{t}+\sum_{k=1}^{3} \rho_{k} Q U A R T E R_{k t}+\sum_{k=1}^{12} \Psi_{k} F R B_{i k}+ \\
& B_{i t-1}\left(\eta+\delta T I M E_{t}+\sum_{j=0}^{4} \phi_{j} \Delta M_{t-j}+\sum_{j=0}^{4} \gamma_{j} \Delta G D P_{t-j}\right)+\epsilon_{i t}
\end{aligned}
$$

where $L_{i t}$ is a bank-level measure of lending activity, $M_{t}$ is a monetary policy indicator, and $B_{i t}$ is a measure of balance sheet strength which we define, following Kashyap and Stein (2000) p. 410, as the ratio of securities plus federal funds sold to total assets. Time effects are captured by a time trend $\left(T I M E_{t}\right)$ and three quarterly seasonal dummies $\left(Q U A R T E R_{k t}\right)$. FRB $B_{i k}$ captures geographical effects via Federal Reserve district dummies while $G D P_{t}$ controls for changes in overall economic activity. ${ }^{4}$

In this specification, KS are interested in the coefficient of $\Delta M_{t-j}$ interacted with $B_{i t-1}$. Intuitively, the less liquid bank will reduce its loans if its lost insured deposits due to a contractionary monetary shock cannot be replenished by other forms of finance. Hence, one would expect to see $\partial^{2} L_{i t} / \partial B_{i t} \partial M_{t}<0$ for banks lacking full access to uninsured sources of funds. To test this hypothesis, KS focus on how small and large banks differ from each other in their ability to raise uninsured forms of financing without frictions and argue that one should concentrate on $\partial^{3} L_{i t} / \partial B_{i t} \partial M_{t} \partial S I Z E_{i t}>$ 0 , the size effects. The sign of this third derivative can be interpreted as implying that the effect of contractionary monetary policy will be strongest for the smallest banks, while the largest banks will be less sensitive, since they have better access to the market for uninsured funds.

Nevertheless, this approach fails to take into account the fact that loans to private borrowers exhibit both market risk and default risk. Default risk is often correlated with macroeconomic conditions as well as with financial-

\footnotetext{
${ }^{4}$ In their analysis, KS also utilize a so-called univariate model which excludes the effects of $G D P$ from the bivariate model. Due to space considerations, we do not present results for the univariate model, which are qualitatively similar to those obtained from the bivariate model. They are available from the authors upon request.
} 
market outcomes such as movements in the cost of short-term funds. In that sense, we argue that the KS model omits an important variable: financial sector uncertainty. Such an omission leads to biased and inconsistent estimates of the model's parameters, and in particular of the effects of monetary policy on banks' behavior. Additionally, the KS model does not incorporate basic bank-specific variables controlling for bank capitalization, holdings of excess capital and membership in a bank holding company which could have an important effect on banks' lending behavior. ${ }^{5}$ To overcome these problems, we develop the following modified bivariate model:

$$
\begin{aligned}
\Delta l o g\left(L_{i t}\right)= & \sum_{j=1}^{4} \alpha_{j} \Delta \log \left(L_{i t-j}\right)+\sum_{j=0}^{4} \mu_{j} \Delta M_{t-j}+\sum_{j=0}^{4} \nu_{j} \sigma(M)_{t-j} \Delta M_{t-j}+ \\
& \sum_{j=0}^{4} \pi_{j} \Delta G D P_{t-j}+\sum_{j=0}^{4} \varphi_{j} \sigma(M)_{t-j} \Delta G D P_{t-j}+\sum_{j=0}^{4} \lambda_{j} \sigma(M)_{t-j}+ \\
& \Theta T I M E_{t}+\sum_{k=1}^{3} \rho_{k} Q U A R T E R_{k t}+\sum_{k=1}^{12} \Psi_{k} F R B_{i k}+ \\
& B_{i t-1}\left(\eta+\delta T I M E_{t}+\sum_{j=0}^{4} \phi_{j} \Delta M_{t-j}+\sum_{j=0}^{4} \gamma_{j} \Delta G D P_{t-j}+\sum_{j=0}^{4} \xi_{j} \sigma(M)_{t-j}\right)+ \\
& \Gamma \mathbf{X}_{i t}+\epsilon_{i t}
\end{aligned}
$$

where $\mathbf{X}_{i t}$ is a vector of bank-specific variables including the capitalization ratio, two measures of excess capital holding 6 and an indicator for the existence of internal capital markets through membership in a bank holding company.

In our specification, a proxy for financial sector uncertainty, $\sigma(M)_{t}$, is integrated into the simple KS approach. Note that $\sigma(M)_{t}$ appears both by itself and in conjunction with a measure of balance sheet strength, $B_{t}$. The

\footnotetext{
${ }^{5}$ See Kishan and Opiela (2000), Ashcraft (2006). We acknowledge the constructive suggestions of an anonymous reviewer on this point.

${ }^{6}$ Following Kishan and Opiela (2000), we use the ratio of equity capital to total assets (capratio) as a measure of bank capital, and construct indicators for adequately capitalized banks $(8 \%<$ capratio $\leq 10 \%)$ and well-capitalized banks (capratio $>10 \%)$. We interact these indicator variables with the bank capitalization ratio for each bank-quarter to investigate whether the effect of capitalization on loan growth varies over these three ranges of bank capital.
} 
latter interaction term allows us to evaluate whether the effect of uncertainty on bank lending behavior differs with respect to the bank's liquidity, whereas the former term captures the direct effect of uncertainty. Our expanded model also contains two other sets of interaction terms: monetary policy-uncertainty and output growth-uncertainty interactions. These terms are incorporated in our empirical model to help us understand the impact of financial sector uncertainty in a more comprehensive way. It is highly likely that uncertainty will affect banks' lending decisions through the stance of monetary policy and the state of the overall economy. ${ }^{7}$ Significant coefficients on the terms including $\sigma(M)_{t}$ imply that these interaction effects have a meaningful impact on loan growth.

\subsection{Identifying financial sector uncertainty}

Any attempt to evaluate the effects of uncertainty $\sigma(M)_{t}$ on banks' lending behavior requires specification of a measure of risk. In this study, we utilize three series derived from daily interest rates to generate measures of financial uncertainty. This approach allows us to control for the robustness of our findings and examine whether our results are driven by the choice of a specific uncertainty proxy. The daily interest rate series we employ to generate a measure of uncertainty include both a level and a spread from Treasury markets, accessed from the DRI-Global Insight Basic Economics database.

\subsubsection{Generating volatility measures from daily data}

A number of competing approaches for the construction of volatility measures may be found in the empirical literature. The choice of a particular specification to generate uncertainty may have a considerable impact on the empirical findings, since counterintuitive results may be merely reflecting errors of measurement in a proxy for risk. It is possible to employ a simple moving standard deviation of the policy series, at the same frequency as the data: for instance, including the past four or eight quarters' of changes in the context of quarterly data. However, this measure gives rise to sub-

\footnotetext{
${ }^{7}$ We would like to thank the reviewer for suggesting that these two variables should be included in our model for a better understanding of the role of uncertainty.
} 
stantial serial correlation in the summary measure. A more sophisticated approach utilises the ability of GARCH models to mimic the "volatility clustering" often found in high-frequency financial series. However, a GARCH model fitted to monthly or quarterly data may find very weak persistence of shocks. Furthermore, a proxy for uncertainty obtained from a GARCH specification will be dependent on the choice of the model and exhibit significant variation over alternatives.

In this study we use (squared) daily changes in the series to capture that quarter's volatility, following a procedure originally proposed by Merton (1980) to better represent the uncertainty facing economic agents. In order to employ the Merton methodology to the problem at hand, we must evaluate the intra-quarterly volatility of the series from daily data. We first take the squared first difference of the daily changes (after dividing by the square root of the number of days intervening), which we then define as the daily contribution to quarterly volatility:

$$
\varsigma_{t}^{d}=\left(100 \frac{\Delta x_{t}}{\sqrt{\Delta \phi_{t}}}\right)^{2},
$$

where the denominator expresses the effect of calendar time elapsing between observations on the $x$ process. If data were available every calendar day, $\Delta \phi_{t}=1, \forall t$, but given that data are not available on weekends and holidays, $\Delta \phi_{t} \in(1,5)$. The estimated quarterly volatility of the monetary policy series is defined as $\Phi_{t}\left[x_{t}\right]=\sqrt{\sum_{t=1}^{T} \varsigma_{t}^{d}}$ where the time index for $\sigma_{t}\left[x_{t}\right]$ is at the quarterly frequency. ${ }^{8}$

Table 1 presents correlations between the volatility series which we consider in the next section (based on the interest rate on the one year and five-year Treasury note, the ten year-one year Treasury term spread) and the Bernanke and Mihov (1998) measure of the stance of U.S. monetary policy $(\mathrm{MonPol})$ discussed below. There are no meaningful correlations among the measures of uncertainty except for that of the term spread and the return on the five-year Treasury note. The measures of financial-sector uncertainty and the stance of monetary policy are, likewise, not significantly correlated.

\footnotetext{
${ }^{8}$ See Baum, Caglayan and Ozkan (2004) for a more detailed discussion of the procedure and its merits.
} 
Uncertainty as measured does not systematically increase in times of contractionary monetary policy.

\subsection{Identifying the stance of monetary policy}

In the context of our study, it is essential to accurately evaluate the stance of monetary policy. A simple approach is to keep track of the changes in the stock of money, but this may be misleading, as the Federal Reserve aims at smoothing short-term interest rates. The problems with this simple approach have led researchers to develop alternative methods for identifying the stance of policy. Although no clear consensus has emerged, some approaches have been highlighted in the recent literature. We have chosen to employ one of the methods used in KS' work: the method developed by Bernanke and Mihov (1998), to measure the overall stance of U.S. monetary policy via a flexible VAR. We construct the VAR system as described in Bernanke-Mihov's work and compute the stance of monetary policy over the extended span of our BHC data. ${ }^{9}$

\section{Empirical findings}

\subsection{Data}

We utilize the Federal Reserve System's Commercial Bank and Bank Holding Company (BHC) database, covering essentially all banks in the U.S. on a quarterly basis from 1986-2000. Our choice of starting period for our empirical analysis is motivated by the fact that data from the early 1980s may be contaminated by excessive movements in monetary policy and in uncertainty proxies during the Volcker period or Regulation Q-type restrictions. Kashyap and Stein claim to have obtained stronger results using a subsample covering 1986Q1-1993Q2 versus the sample going back to 1976, so our sample perhaps places their specification in the best light. The degree of concentration in the U.S. banking industry increased considerably over the period under study, implying that a very large fraction of the observations in

\footnotetext{
${ }^{9}$ Comparison of our computed Bernanke-Mihov measure over the longer sample and that published in their article (which ends in 1997) indicates that the two series are similar.
} 
the "all banks" data set are associated with quite small, local institutions. ${ }^{10}$ Using this data set we construct our key variables following the recommendation provided in KS' appendix to ensure consistency and eliminate any potential definitional discrepancies. The dependent variable in our analysis is the growth rate of loans. We must avoid mistaking extreme growth rates caused by mergers, acquisitions or divestitures for the performance of a single bank that has not undergone such organizational changes. Accordingly, we also eliminate bank-quarter observations that register a substantial increase or decrease in their lending activity by trimming the distribution of bank loan growth rates at the 2.5 and 97.5 percentiles per calendar quarter.

We provide basic descriptive statistics on our variables in Table 2. The number of observations referenced is the number of bank-quarters in the panel. The first several lines refer to our constructed measures of uncertainty $\left(\sigma(M)_{t}\right)$ while $\Delta m b m$ represents the Bernanke-Mihov measure of the stance of monetary policy. The dependent variable in our model is the growth rate of total loans (for which we have around 640,000 observations) or commercial and industrial (C\&I) loans (for which we have around 612,000 observations). Finally, the $B$ and cap. ratio variables represent a proxy for the strength of a bank's balance sheet and capitalization ratio, respectively. The following panels of Table 2 present the bank-specific variables for the small, medium, and large size categories, respectively, for both total loans and C\&I loans. The thresholds for these definitions are the 95th and 99th percentile of total assets, evaluated each quarter. Thus, a particular bank may appear in different categories over time.

We see that the small banks (in terms of average or median values) have the most liquid balance sheet, with a value for $B$ more than $50 \%$ larger than that of large banks. This observation holds whether we concentrate on the behavior of total loans or that of C\&I loans. Although the average growth rates of total loans and $C \& I$ loans are greater for large banks than they are for medium and small banks, it is interesting to note that small banks in the upper quartile exhibit higher loan growth rate than large banks. Finally, the

\footnotetext{
${ }^{10}$ Over 15,000 banks were required to file condition reports in 1986 . By 2000Q4, the number of reporting banks fell to 8,956 . We take membership in a bank holding company into account to control for the existence of internal capital markets.
} 
capitalization ratio is highest for small banks and lowest for large banks.

In the following subsections, we present our results. We first consider the bivariate KS model over our 1986-2000 sample period. We then integrate financial sector uncertainty into the original specification and investigate its impact on bank lending behavior for small, medium and large banks in conjunction with the stance of monetary policy. We employ each of the volatility series described above in our analysis to check for the robustness of our results. The augmented model also contains the bank-specific variables mentioned earlier.

\subsection{Empirical methodology}

Estimation of the models utilized in this study requires consideration of several econometric issues. In replicating the original KS model specification, we use the same estimation technique, pooled ordinary least squares (OLS), used in their study. In our augmented model, we have added not only measures of financial sector uncertainty but also several additional bank-specific variables. Those variables prove to have significant explanatory power in most of the models presented in Tables 4 and $5 .{ }^{11}$ We can reject the hypothesis that the effect of capitalization on loan growth is constant over the three ranges of bank capital ratios (see footnote 9 ).

However, these additional bank-specific variables - particularly the capitalization ratio - are not likely to satisfy the assumption of exogeneity required by OLS methods. Accordingly, the estimates of our augmented model are computed using instrumental variables (IV) estimation techniques. We instrument the first lag of the dependent variable, the capitalization ratio and the two excess capital measures with the fifth lag of the dependent variable and the first lags of the capitalization measures.

We perform several tests on the adequacy of this estimation method. The IV estimates are compared to the equivalent pooled OLS model using a Durbin-Wu-Hausman test of exogeneity. ${ }^{12}$ The null hypothesis of that test states that OLS estimation is appropriate, while rejection favors IV meth-

\footnotetext{
${ }^{11}$ For brevity, their coefficient estimates are not reported in the tables, but are available on request.

${ }^{12}$ See Baum, Schaffer and Stillman (2003), pp. 20-22.
} 
ods. We construct estimates of the variance-covariance matrix $(V C E)$ of estimated parameters using the cluster-robust $V C E$ estimator, using bank as the clustering variable. This estimator allows for arbitrary heteroskedasticity among banks (as do "White" robust standard errors) and relaxes the assumption that the error covariance matrix is diagonal, allowing for nonindependence of errors at the bank level. ${ }^{13,14}$ As the presence of first-order autocorrelated errors would be problematic, we also perform the ArellanoBond test for first-order autocorrelation in a panel context. ${ }^{15}$ Finally, instrumental variables estimates are not reliable if the instruments are "weak": if they fail to numerically identify the parameters. We perform the Kleibergen and Paap (2006) rk Lagrange Multiplier test, which has the null hypothesis that the model is underidentified. ${ }^{16}$ A rejection indicates that the instruments are strong enough to reliably identify the parameters.

We summarize the results of these tests here. The test statistics and $p$-values are not reported in the tables for brevity, but are available on request. In the preponderance of estimated equations reported in Tables 4 and 5, the Durbin-Wu-Hausman (DWH) test strongly rejects its null, indicating that IV estimation is required to produce consistent point and interval estimates. In those cases (chiefly the equations for large banks) in which the DWH null is not rejected, IV estimates are consistent if possibly inefficient. We maintain the same IV estimation technique throughout for comparability. The Arellano-Bond AR(1) test fails to reject the null of zero first-order autocorrelation in all equations reported in Tables 4 and 5. The Anderson LR test rejects the null of underidentification in all equations, indicating that the instruments are serving their purpose of identifying the model's parameters.

\footnotetext{
${ }^{13}$ For more detail, see Baum (2006), pp. 138-139.

${ }^{14}$ Although KS' results are generated with robust standard errors, we employ the clusterrobust $V C E$ estimator in Table 3 for consistency with our later results.

${ }^{15}$ This test is performed with Stata's abar command, developed by Roodman (2007).

${ }^{16}$ See Baum, Schaffer and Stillman (2007), Section 7.2.
} 


\subsection{Replicating the KS model}

We start our investigation by replicating the KS analysis using our data set and examine whether changes in monetary policy have an effect on the sensitivity of lending activity to balance sheet strength, $\partial^{2} L_{i t} / \partial B_{i t} \partial M_{t}$, for small, medium and large size classes. Hence, similar to KS, for each quarter we create small, medium and large size classes based on banks' total asset distribution. Small banks are those whose total assets are less than the 95th percentile; medium banks' assets range between the 95th percentile and the 99th percentile; large banks' assets are above the 99th percentile. We then estimate the bivariate model given in equation (1).

To discuss our findings and be able to compare them with those of KS, for each model, we compute the sums of the $\mu$ (labeled MPI) and $\phi$ coefficients on the monetary policy indicator (labeled $B \cdot M P I) .{ }^{17}$ Table 3 gives the results for total loans and C\&I loans using the standard KS approach. In comparison to those results presented in KS (2000, Table 5, Panel B, p. 422), results for total loans depicted in Table 3 show that the summary measure for $B \cdot M P I$ is insignificant for all size classes of banks. This finding from our more recent sample period refutes the presence of the bank lending channel for the US. In contrast, results for C\&I loans depicted in Table 3 provide support for the bank lending view. The sum of the $B \cdot M P I$ coefficients is negative and significant for small banks, positive and significant for medium banks but not distinguishable from zero for large banks. Given that KS stress their results for C\&I loans when they discuss their empirical evidence, we conclude that our extended data (using their model) provide support for the presence of a bank lending channel for the US.

\footnotetext{
${ }^{17}$ In Tables $3-5$, we provide the sum of the $\mu$ coefficients giving the primary effects of monetary policy but for brevity refrain from any discussion. To compute the overall impact of monetary policy on bank loan growth, one must consider both this sum as well as the secondary effect expressed by the $\phi$ coefficients multiplied by a specific level of $B$, the balance sheet strength measure.
} 


\subsection{The modified KS model: Investigating the effects of un- certainty}

Our next set of results utilizes equation (2) in which we incorporate the effects of uncertainty for each size class along with several bank specific variables. In particular, we examine whether uncertainty has an impact on bank lending behavior and also whether this impact changes depending on banks' balance sheet strength, $\partial L_{i t} / \partial \sigma(M)_{t}$ and $\partial^{2} L_{i t} / \partial B_{i t} \partial \sigma(M)_{t}$. We would like to note that our regressions also contain additional interaction terms of uncertainty to capture the impact of uncertainty on bank lending which can affect bank behavior through monetary policy $\left(\sigma(M)_{t-j} \Delta M_{t-j}\right)$ and output movements $\left(\sigma(M)_{t-j} \Delta G D P_{t-j}\right)$. Although we do not provide summary measures of their coefficients in Tables 4 and 5 , we take into account the role of monetary policy and output, as we explain in section 4.4.3 below, in the construction of the values presented in Tables 6 and 7 .

\subsubsection{The extended bivariate specification for total loans}

Table 4 presents results for the modified bivariate model of equation (2) which uses the growth of total loans as the dependent variable and employs three different proxies to capture the presence of financial uncertainty: those based on the one-year and five-year Treasury note and the ten year-one year Treasury term spread, respectively. The table presents the sums of the $\mu$ (labeled $M P I$ ) and $\phi$ coefficients on the monetary policy indicator (labeled $B \cdot M P I)$ in conjunction with the bank's balance sheet strength, the sum of the $\lambda$ coefficients on uncertainty $\sigma(M)_{t}$ (labeled $\sigma$ ), and the sum of the $\xi$ coefficients on uncertainty interacted with bank balance sheet strength $B_{i t} \sigma(M)_{t}$ (labeled $\left.B \cdot \sigma\right)$, for each size category.

In search for the presence of a bank lending channel, we initially inspect the sum of the $\phi$ coefficients on $B \cdot M P I$. For small banks, this sum is negative and significant at the $1 \%$ and $10 \%$ level when we use uncertainty measures based on five-year Treasury rates and term spreads, respectively. The same coefficient is negative but insignificant when we use the one-year Treasury uncertainty measure. For medium and large banks the sum is insignificant yet it takes a positive sign for medium banks and a negative 
sign for large banks. In contrast to results presented in Table 3 for the original KS specification and econometric approach, these results for total loans provide support for the presence of a bank lending channel for the US.

Next, we turn our attention to understanding the direct impact of financial sector uncertainty on banks' total loan growth by considering the sum of $\lambda$ estimates $(\sigma)$, which captures the primary effect of uncertainty on bank lending behavior, and the sum of $\xi$ estimates $(B \cdot \sigma)$, which captures the secondary effect of uncertainty through the bank balance sheet. ${ }^{18}$ The sum of $\lambda$ estimates on uncertainty is positive and significant at the $1 \%$ level in all models for the small bank category. The same coefficient is positive and significantly different from zero in two cases for the large bank category. For the medium banks, we do not obtain any significance for the same coefficient. This result suggests that uncertainty has a direct positive impact on bank lending. During times of greater uncertainty, small and large banks are inclined to increase their total lending activities.

Uncertainty can also affect banks' lending behavior directly through its interaction with the strength of the bank balance sheet. We find that the sign of the derivative $\partial^{2} L_{i t} / \partial B_{i t} \partial \sigma(M)_{t}$ is negative for all bank sizes and significant except for two occasions. This secondary effect implies that as uncertainty increases, banks with more-liquid assets tend to reduce their loans by a larger amount than do similarly-sized banks with less-liquid assets.

However, focusing only on the two sets of terms described above, we cannot make a conclusive decision regarding the total effect of uncertainty on bank lending activity. To comprehend the overall impact of uncertainty on banks' lending behavior, we must incorporate those additional effects of uncertainty which affect banks through monetary policy and output as shown in equation (2). We discuss the total impact of uncertainty on bank lending in Tables 6 and 7 below, after we depict our results for C\&I loans.

\footnotetext{
${ }^{18}$ As mentioned above, Equation (3) also includes interaction terms of money growth and output growth with uncertainty. They are not reported in Tables 4 and 5 but enter the computations of the total effects of uncertainty in Tables 6 and 7 .
} 


\subsubsection{The extended bivariate specification for C\&I loans}

In this section we present our empirical results for C\&I loans obtained from the modified bivariate model. We initially concentrate on the presence of bank lending channel. Inspection of Table 5 shows that the sum of $\phi(B$. $M P I)$ estimates is negative for almost all bank categories; it is positive for two cases for the medium banks. However, in none of those cases is this coefficient significant. In contrast to KS' findings and the importance they that attach to C\&I loans' behavior, the failure to find support for a bank lending channel for this major loan category is a major setback to their conclusions.

Next we concentrate our attention on the relationship between banks' C\&I loan activity and financial sector uncertainty. Table 5 provides evidence that financial sector uncertainty has an important direct impact on all banks' C\&I lending behavior. We find that the sum of $\lambda$ coefficients (denoted $\sigma$ ) is almost always significant. While this impact is positive and significant for the one-year and five-year Treasury rate-based uncertainty measures, it is negative for the term-spread uncertainty measure. We suspect that the primary effects of uncertainty on banks' lending behavior may be driven by the term structure of bank loans. ${ }^{19}$ In contrast to Table 4 , we find that uncertainty does not affect C\&I lending through banks' balance sheet strength. The sum of $\xi$ coefficients (denoted $B \cdot \sigma$ ), although consistently negative for all bank categories, it is significant only for the small bank category when the one-year Treasury rate is used to define the measure of uncertainty.

\subsubsection{The total impact of uncertainty on bank lending}

To understand the total impact of uncertainty on bank lending, we must simultaneously consider the direct and indirect effects of uncertainty taking account of effects through changes in monetary policy and output growth. These effects can be captured by inspecting the sums of $\lambda, \xi, \nu$ and $\varphi$ estimates, respectively, while considering the stance of a bank's balance sheet

\footnotetext{
${ }^{19}$ Unfortunately, we do not have detailed information on the term structure of individual banks' loan portfolios.
} 
strength, monetary policy and output. In Tables 6 and 7, we provide the total effects of uncertainty on lending behavior for each size category for total and C\&I loans, respectively. The tables are constructed by averaging over the three uncertainty proxies to remove the dependence of these sensitivity measures on a specific proxy. To evaluate the impact of uncertainty in various states of monetary policy and output, given the data, we compute low $\left(25^{\text {th }}\right.$ percentile) and high $\left(75^{\text {th }}\right.$ percentile) values for the monetary policy indicator and output growth rate. ${ }^{20}$ The first three columns of each table report the $25^{t h}, 50^{t h}$, and $75^{t h}$ percentiles of banks' balance sheet strength (liquidity) across all size categories. The next three columns lay out the total long-run sensitivity of lending behavior to bank strength with respect to changes in uncertainty. For example, we compute Total $\left[\sigma \mid B_{p 25}\right]=$ $\left(\sum_{j=0}^{4} \lambda_{j}+\nu_{j}+\varphi_{j}\right)+B_{p 25} \cdot\left(\sum_{j=0}^{4} \xi_{j}\right)$ where $B_{p 25}$ is the level of banks' balance sheet strength measured at the $25^{\text {th }}$ percentile. The sums of $\lambda, \xi, \nu$ and $\varphi$ estimates correspond to those estimated in equation (2).

Given this background, we can now interpret our results. A cursory glance at Table 6 reveals that total loans generally increase as uncertainty increases. From Table 7, it is harder to summarize the impact of uncertainty on C\&I loans as there are certain states in which banks would increase their C\&I loans and other states in which they would not. Overall, larger banks tend to alter their loan portfolios more than their smaller counterparts during times of greater uncertainty. This observation is sensible as one could expect that larger banks would have better and more sophisticated risk management strategies than their smaller counterparts (see Gatev and Strahan (2003)).

Finally, Tables 6 and 7 provide evidence that banks with lower liquidity increase their lending in response to higher uncertainty while those with higher liquidity either reduce their lending or increase it by a smaller amount. This may reflect the more-liquid banks' concerns for a prudent response in

\footnotetext{
${ }^{20}$ The results in these tables are prescriptive and do not necessarily reflect the way monetary policy and output evolve over time. It is well known that monetary policy authorities react to the state of the economy. Although we cannot study such subtleties within our construct, we believe that the results presented in Tables 6 and 7 are informative as they show banks' reaction to uncertainty in extreme cases as reflected in the estimated parameters from our model.
} 
more turbulent times. Those banks already have exhibited a lesser appetite for risky assets, and their response may reflect those preferences.

\section{Conclusions}

In this paper we re-examine the effects of changes in the stance of monetary policy on banks' lending activities while considering the impact of financial sector uncertainty in that relationship. Similar to Kashyap and Stein (2000), we concentrate on the growth rates of total loans and commercial and industrial loans for various size categories. To carry out our investigation, we use the Federal Reserve System's Commercial Bank and Bank Holding Company database which contains information on all banks regulated by the Federal Reserve System, the Federal Deposit Insurance Corporation, and the Comptroller of the Currency. Our data set covers the period between 1986-2000 on a quarterly basis, with 8,900-15,000 observations per quarter.

We start our analysis by investigating whether KS' findings receive support from our more recent data set. We then extend their model by incorporating the effects of financial sector uncertainty along with several bank-specific control variables. We observe that an increase in uncertainty generally leads larger banks to increase their loans more than their smaller counterparts. A stronger finding is on the relationship between lending activity and bank liquidity. We observe that banks holding more liquid assets alter their lending by a smaller amount (and may curtail their lending) relative to those banks which are less liquid. When we look for evidence in search of a bank lending channel, we find only weak support for such a channel with respect to total loans, and none whatsoever with respect to C\&I loans.

Given our results, we must stress the importance of choosing an appropriate model and empirical methodology. ${ }^{21}$ The conclusions of Kashyap and Stein (2000) emphasize their findings of a bank lending channel for C\&I loans in the US. Using an extended specification of the model allowing for financial sector uncertainty, we find that their findings are subject to doubt. The

\footnotetext{
${ }^{21} \mathrm{We}$ are grateful to an anonymous reviewer for various suggestions to improve the model.
} 
importance of uncertainty terms in our model implies that the KS model is seriously misspecified, leading to biased findings. The same critique may be levelled at the findings of several studies that have followed in KS' footsteps as those studies also failed to incorporate variables that capture uncertainty in the financial markets or control for bank-specific factors. Hence, we conclude that any investigation of the bank lending channel should consider the potential importance of financial sector uncertainty on this relationship. 


\section{References}

Ashcraft, A. B. (2006), 'New evidence on the lending channel', The Journal of Money, Credit and Banking 38(3), 751-775.

Baum, C. F. (2006), An Introduction to Modern Econometrics Using Stata, Stata Press, College Station, TX.

Baum, C. F., Caglayan, M. and Ozkan, N. (2004), 'Nonlinear effects of exchange rate volatility on the volume of bilateral exports', Journal of Applied Econometrics 19, 1-23.

Baum, C. F., Schaffer, M. E. and Stillman, S. (2003), 'Instrumental variables and GMM: Estimation and testing', Stata Journal 3, 1-31.

Baum, C. F., Schaffer, M. E. and Stillman, S. (2007), 'Enhanced routines for instrumental variables/generalized method of moments estimation and testing', Stata Journal 7(4), 465-506.

Bernanke, B. and Mihov, I. (1998), 'Measuring Monetary Policy', Quarterly Journal of Economics 113, 869-902.

Bernanke, B. S. and Blinder, A. S. (1992), 'The Federal Funds rate and the channels of monetary transmission', American Economic Review 82, 901-21.

Bernanke, B. S. and Gertler, M. (1995), 'Inside the black box: The credit channel of monetary policy transmission', Journal of Economic Perspectives $\mathbf{9}, 27-48$.

Calomiris, C. W., Himmelberg, C. P. and Wachtel, P. (1995), 'Commercial paper, corporate finance, and the business cycle: A microeconomic perspective', Carnegie-Rochester Conference Series on Public Policy 42, 203-50.

Ehrmann, M., Gambacorta, L., Martinez-Pags, J., Sevestre, P. and Worms, A. (2003), 'The effects of monetary policy in the euro area', Oxford Review of Economic Policy 19(1), 58-72.

Gatev, E. and Strahan, P. E. (2003), Banks' Advantage in Hedging Liquidity Risk: Theory and Evidence from the Commercial Paper Market, working paper 9956, NBER.

Gertler, M. and Gilchrist, S. (1994), 'Monetary policy, business cycles, and the behavior of small manufacturing firms', Quarterly Journal of Economics 109, 309-40. 
Kashyap, A. K. and Stein, J. C. (2000), 'What do a million observations on banks say about the transmission of Monetary Policy?', American Economic Review 90, 407-28.

Kashyap, A. K., Stein, J. C. and Wilcox, D. W. (1993), 'Monetary policy and credit conditions: Evidence from the composition of external finance', American Economic Review 83, 78-98.

Kashyap, A. K., Stein, J. C. and Wilcox, D. W. (1996), 'Monetary policy and credit conditions: Evidence from the composition of external finance: Reply', American Economic Review 86, 310-14.

Kishan, R. P. and Opiela, T. P. (2000), 'Bank size, bank capital, and the bank lending channel', Journal of Money, Credit and Banking 32(1), 121-41.

Kleibergen, F. and Paap, R. (2006), 'Generalized reduced rank tests using the singular value decomposition', Journal of Econometrics 127(1), 97126.

Merton, R. C. (1980), 'On estimating the expected return on the market: An exploratory investigation', Journal of Financial Economics 8, 323-61.

Nielsen, J. (2002), 'Trade Credit and the Bank Lending Channel', Journal of Money, Credit and Banking 34, 226-53.

Peek, J. and Rosengren, E. S. (1995), Bank lending and the transmission of monetary policy, in J. Peek and E. S. Rosengren, eds, 'Is bank lending important for the transmission of monetary policy?', number 39, Federal Reserve Bank of Boston Conference Series, pp. 47-68.

Roodman, D. M. (2007), 'XTABOND2: Stata module to extend xtabond dynamic panel data estimator', available at: http://ideas.repec.org/c/boc/bocode/s435901.html. Accessed 14 March 2007.

Stein, J. C. (1998), 'An adverse-selection model of bank asset and liability management with implications for the transmission of monetary policy', RAND Journal of Economics 29, 466-86. 
Table 1: Correlations of time series measures, 1986q1-2000q4

\begin{tabular}{ccccc}
\hline Mon Pol & 1.0000 & & & \\
Vol(Tr1yr) & -0.0286 & 1.0000 & & \\
Vol(Tr5yr) & -0.1237 & 0.8285 & 1.0000 & \\
Vol(10yr-1yr) & -0.1048 & 0.6637 & 0.6156 & 1.0000 \\
\hline & Mon Pol & Vol(Tr1yr) & Vol(Tr5yr) & Vol(10yr-1yr) \\
\hline
\end{tabular}


Table 2: Descriptive statistics, 1986Q1-2000Q4

\begin{tabular}{lrrrrrr}
\hline$\sigma(M)$ & $N$ & $\mu$ & $\sigma$ & $p 25$ & $p 50$ & $p 75$ \\
\hline 1-year Treasury & 42.3283 & 14.9172 & 32.5551 & 42.3399 & 48.6527 \\
5-year Treasury & 48.0072 & 13.4216 & 38.5120 & 45.7092 & 53.1876 \\
Tr10yr-Tr1yr spread & & 30.6889 & 8.5777 & 24.3619 & 29.5070 & 34.4565 \\
$\Delta m b m$ & & -0.0008 & 0.0155 & -0.0057 & -0.0017 & 0.0077 \\
\hline
\end{tabular}

(A) Total Loans

All banks

\begin{tabular}{lcrrrrr}
\hline$\Delta \log$ totloans & 639,861 & 0.0194 & 0.0513 & -0.0109 & 0.0169 & 0.0462 \\
$B$ & & 0.3239 & 0.1560 & 0.2113 & 0.3063 & 0.4226 \\
Cap. ratio & & 0.0945 & 0.0387 & 0.0736 & 0.0868 & 0.1062 \\
Small banks & & & & & & \\
\hline$\Delta \log$ totloans & 614,113 & 0.0194 & 0.0514 & -0.0110 & 0.0169 & 0.0464 \\
$B$ & & 0.3275 & 0.1558 & 0.2151 & 0.3103 & 0.4267 \\
Cap. ratio & & 0.0952 & 0.0388 & 0.0743 & 0.0875 & 0.1070 \\
Medium banks & & & & & & \\
\hline$\Delta \log$ totloans & 20,527 & 0.0193 & 0.0483 & -0.0083 & 0.0170 & 0.0425 \\
$B$ & & 0.2479 & 0.1393 & 0.1569 & 0.2309 & 0.3206 \\
Cap. ratio & & 0.0796 & 0.0368 & 0.0626 & 0.0721 & 0.0863 \\
Large banks & & & & & & \\
\hline$\Delta \log$ totloans & 5,221 & 0.0199 & 0.0507 & -0.0092 & 0.0165 & 0.0432 \\
$B$ & & 0.1981 & 0.1067 & 0.1234 & 0.1905 & 0.2565 \\
Cap. ratio & & 0.0688 & 0.0202 & 0.0563 & 0.0657 & 0.0774 \\
\hline
\end{tabular}

(B) C\&I Loans

All banks

\begin{tabular}{lcccccc}
\hline$\Delta \log C \& I$ loans & 611,561 & 0.0155 & 0.1287 & -0.0556 & 0.0113 & 0.0829 \\
$B$ & & 0.3253 & 0.1539 & 0.2137 & 0.3073 & 0.4227 \\
Cap. ratio & & 0.0940 & 0.0366 & 0.0735 & 0.0866 & 0.1058 \\
Small banks & & & & & & \\
\hline$\Delta \log C \& I$ loans & 587,322 & 0.0154 & 0.1299 & -0.0567 & 0.0111 & 0.0840 \\
$B$ & & 0.3289 & 0.1538 & 0.2174 & 0.3114 & 0.4268 \\
Cap. ratio & & 0.0947 & 0.0366 & 0.0742 & 0.0873 & 0.1066 \\
Medium banks & & & & & & \\
\hline$\Delta \log C \& I$ loans & 19,090 & 0.0166 & 0.1013 & -0.0350 & 0.0153 & 0.0657 \\
$B$ & & 0.2494 & 0.1339 & 0.1616 & 0.2330 & 0.3199 \\
Cap. ratio & & 0.0777 & 0.0324 & 0.0623 & 0.0715 & 0.0848 \\
Large banks & & & & & & \\
\hline$\Delta \log C \& I$ loans & 5,149 & 0.0207 & 0.0857 & -0.0222 & 0.0168 & 0.0575 \\
$B$ & & 0.1981 & 0.1029 & 0.1255 & 0.1906 & 0.2544 \\
Cap. ratio & & 0.0683 & 0.0195 & 0.0562 & 0.0655 & 0.0770 \\
\hline
\end{tabular}

Note: $N$ refers to the number of bank-quarters in the category. $p 25, p 50$ and $p 75$ represent the quartiles of the distribution of each variable, while $\mu$ and $\sigma$ are the mean and standard deviation. 
Table 3: Pooled OLS estimates for total and C\&I loans : Sums of coefficients on monetary policy indicator, 1986Q1-2000Q4

\begin{tabular}{lrccrcc}
\hline & \multicolumn{3}{c}{ Total Loans } & \multicolumn{3}{c}{ C\&I Loans } \\
Size & {$[N]$} & $M P I$ & $B \cdot M P I$ & {$[N]$} & $M P I$ & $B \cdot M P I$ \\
\hline Small & {$[576,108]$} & -0.148 & 0.004 & {$[497,834]$} & -0.027 & -0.438 \\
& & $(0.022)^{* * *}$ & $(0.060)$ & & $(0.064)$ & $(0.176)^{* *}$ \\
\hline Med. & {$[21,117]$} & -0.230 & 0.499 & {$[21,585]$} & -0.310 & 1.358 \\
& & $(0.104)^{* *}$ & $(0.400)$ & & $(0.200)$ & $(0.808)^{*}$ \\
\hline Large & {$[5,257]$} & 0.294 & -1.592 & {$[5,681]$} & -0.167 & 0.837 \\
& & $(0.226)$ & $(1.106)$ & & $(0.401)$ & $(1.891)$ \\
\hline
\end{tabular}

Note: $N$ refers to the number of bank-quarters in the category.

Cluster-robust standard errors in parentheses. *: 10\%, **: 5\%, ***: $1 \%$. 
Table 4: Instrumental variables estimates, bivariate model for total loans: Sums of coefficients on monetary policy indicator and uncertainty, 1986Q12000Q4

\begin{tabular}{llllll}
$\sigma$ calc. from & Size & $M P I$ & $B \cdot M P I$ & $\sigma$ & $B \cdot \sigma$ \\
\hline One-year & Small & -1.774 & -0.134 & 0.048 & -0.075 \\
Treas. note & & $(0.154)^{* * *}$ & $(0.086)$ & $(0.004)^{* * *}$ & $(0.008)^{* * *}$ \\
& Med. & 0.244 & 0.655 & 0.023 & -0.081 \\
& & $(0.687)$ & $(0.596)$ & $(0.020)$ & $(0.048)^{*}$ \\
& Large & -0.017 & -1.226 & 0.145 & -0.273 \\
& & $(2.080)$ & $(1.717)$ & $(0.374)^{* * *}$ & $(0.133)^{* *}$ \\
\hline Five-year & Small & 0.697 & -0.403 & 0.057 & -0.094 \\
Treas. note & & $(0.177)^{* * *}$ & $(0.092)^{* * *}$ & $(0.005)^{* * *}$ & $(0.012)^{* * *}$ \\
& \multirow{2}{*}{ Med. } & 0.245 & 0.062 & 0.036 & -0.163 \\
& & $(1.022)$ & $(0.626)$ & $(0.023)$ & $(0.070)^{* *}$ \\
& Large & 5.939 & -2.198 & 0.109 & -0.323 \\
& & $(2.318)^{* * *}$ & $(1.923)$ & $(0.048)^{* *}$ & $(0.184)^{*}$ \\
\hline Ten-year- & Small & -1.384 & -0.160 & 0.024 & -0.112 \\
One-year & & $(0.110)^{* * *}$ & $(0.095)^{*}$ & $(0.008)^{* * *}$ & $(0.017)^{* * *}$ \\
Treas. spread & Med. & -1.010 & 0.083 & -0.003 & -0.108 \\
& & $(0.613)^{*}$ & $(0.679)$ & $(0.042)$ & $(0.102)$ \\
& Large & -3.820 & -1.527 & 0.048 & -0.026 \\
& & $(1.180)^{* * *}$ & $(1.181)$ & $(0.089)$ & $(0.237)$ \\
\hline
\end{tabular}

Note: cluster-robust standard errors in parentheses. ${ }^{*}: 10 \%,{ }^{* *}: 5 \%,{ }^{* * *}$ : $1 \%$. 
Table 5: Instrumental variables estimates, bivariate model for C\&I loans: Sums of coefficients on monetary policy indicator and uncertainty, 1986Q12000Q4

\begin{tabular}{llllll}
$\sigma$ calc. from & Size & $M P I$ & $B \cdot M P I$ & $\sigma$ & $B \cdot \sigma$ \\
\hline One-year & Small & 1.169 & -0.152 & 0.136 & -0.070 \\
Treas. note & & $(0.426)^{* * *}$ & $(0.214)$ & $(0.010)^{* * *}$ & $(0.022)^{* * *}$ \\
& Med. & 0.307 & 1.020 & 0.108 & -0.036 \\
& & $(1.836)$ & $(0.985)$ & $(0.042)^{* * *}$ & $(0.107)$ \\
& Large & 4.398 & -0.838 & 0.225 & -0.311 \\
& & $(3.152)$ & $(2.346)$ & $(0.072)^{* * *}$ & $(0.252)$ \\
\hline Five-year & Small & 4.137 & -0.215 & 0.130 & -0.023 \\
Treas. note & & $(0.499)^{* * *}$ & $(0.227)$ & $(0.012)^{* * *}$ & $(0.030)$ \\
& \multirow{2}{*}{ Med. } & 2.859 & 0.434 & 0.076 & -0.022 \\
& & $(2.282)$ & $(1.105)$ & $(0.051)$ & $(0.165)$ \\
& Large & 7.567 & -1.416 & 0.156 & -0.344 \\
& & $(3.407)^{* *}$ & $(2.482)$ & $(0.081)^{*}$ & $(0.323)$ \\
\hline Ten-year- & Small & -3.360 & -0.261 & -0.140 & -0.046 \\
One-year & & $(0.298)^{* * *}$ & $(0.242)$ & $(0.020)^{* * *}$ & $(0.042)$ \\
Treas. spread & Med. & 0.364 & -0.122 & -0.156 & -0.061 \\
& & $(1.244)$ & $(1.078)$ & $(0.088)^{*}$ & $(0.188)$ \\
& Large & -5.224 & -0.104 & -0.014 & -0.355 \\
& & $(2.192)^{* *}$ & $(2.479)$ & $(0.137)$ & $(0.368)$ \\
\hline Note: cluster-robust standard errors in parentheses. *: $10 \%, * *: 5 \%, * * *$ \\
1\%.
\end{tabular}


Table 6: Bivariate model for total loans: Total effect of $\sigma$ for quartiles of $B$, 1986Q1-2000Q4, evaluated at $25^{\text {th }}$ and $75^{\text {th }}$ percentiles of $\Delta M$ and $\triangle G D P$

\begin{tabular}{llrrrrrr}
\hline$\Delta M$ & $\Delta G D P$ & $B_{p 25}$ & $B_{p 50}$ & \multicolumn{1}{c}{$B_{p 75}$} & Total $\left[\sigma \mid B_{p 25}\right]$ & Total $\left[\sigma \mid B_{p 50}\right]$ & Total $\left[\sigma \mid B_{p 75}\right]$ \\
\hline Low & Low & 0.1963 & 0.3006 & 0.4219 & 0.0127 & 0.0034 & -0.0073 \\
Low & High & 0.1963 & 0.3006 & 0.4219 & 0.0061 & -0.0032 & -0.0139 \\
High & Low & 0.1963 & 0.3006 & 0.4219 & 0.0367 & 0.0275 & 0.0168 \\
High & High & 0.1963 & 0.3006 & 0.4219 & 0.0301 & 0.0209 & 0.0102 \\
\hline & \multicolumn{7}{c}{ B. Medium banks } \\
Low & Low & 0.0714 & 0.1929 & 0.2931 & 0.0206 & 0.0070 & -0.0041 \\
Low & High & 0.0714 & 0.1929 & 0.2931 & 0.0255 & 0.0119 & 0.0008 \\
High & Low & 0.0714 & 0.1929 & 0.2931 & 0.0138 & 0.0003 & -0.0109 \\
High & High & 0.0714 & 0.1929 & 0.2931 & 0.0187 & 0.0052 & -0.0060 \\
\hline & & & \multicolumn{7}{c}{ C. Large banks } \\
Low & Low & 0.0723 & 0.1621 & 0.2391 & 0.0636 & 0.0422 & 0.0238 \\
Low & High & 0.0723 & 0.1621 & 0.2391 & 0.0186 & -0.0028 & -0.0211 \\
High & Low & 0.0723 & 0.1621 & 0.2391 & 0.0541 & 0.0327 & 0.0143 \\
High & High & 0.0723 & 0.1621 & 0.2391 & 0.0091 & -0.0123 & -0.0306 \\
\hline
\end{tabular}

Note: Rows are labelled with percentiles of the monetary policy indicator $(\Delta M)$ and GDP growth $(\Delta G D P) . B$ quartiles are calculated from bankquarters entering the regressions reported in Table 4. Effects are averaged over the three financial uncertainty proxies. 
Table 7: Bivariate model for C\&I loans: Total effect of $\sigma$ for quartiles of $B$, 1986Q1-2000Q4, evaluated at $25^{\text {th }}$ and $75^{\text {th }}$ percentiles of $\Delta M$ and $\triangle G D P$

\begin{tabular}{llrrrrrr}
\hline$\Delta M$ & $\Delta G D P$ & $B_{p 25}$ & $B_{p 50}$ & $B_{p 75}$ & Total $\left[\sigma \mid B_{p 25}\right]$ & Total $\left[\sigma \mid B_{p 50}\right]$ & Total $\left[\sigma \mid B_{p 75}\right]$ \\
\hline & & & \multicolumn{5}{c}{ A. Small banks } \\
Low & Low & 0.2071 & 0.3058 & 0.4230 & 0.0549 & 0.0498 & 0.0437 \\
Low & High & 0.2071 & 0.3058 & 0.4230 & 0.0253 & 0.0202 & 0.0142 \\
High & Low & 0.2071 & 0.3058 & 0.4230 & 0.0280 & 0.0230 & 0.0169 \\
High & High & 0.2071 & 0.3058 & 0.4230 & -0.0015 & -0.0066 & -0.0126 \\
\hline Low & Low & 0.1523 & 0.2273 & 0.3153 & 0.0355 & 0.0328 & 0.0295 \\
Low & High & 0.1523 & 0.2273 & 0.3153 & 0.0087 & 0.0060 & 0.0027 \\
High & Low & 0.1523 & 0.2273 & 0.3153 & -0.0074 & -0.0101 & -0.0134 \\
High & High & 0.1523 & 0.2273 & 0.3153 & -0.0342 & -0.0370 & -0.0402 \\
\hline & & & & C. Large banks & & \\
Low & Low & 0.1177 & 0.1865 & 0.2517 & 0.0992 & 0.0765 & 0.0551 \\
Low & High & 0.1177 & 0.1865 & 0.2517 & 0.0336 & 0.0109 & -0.0106 \\
High & Low & 0.1177 & 0.1865 & 0.2517 & 0.0127 & -0.0099 & -0.0314 \\
High & High & 0.1177 & 0.1865 & 0.2517 & -0.0529 & -0.0756 & -0.0970 \\
\hline
\end{tabular}

Note: Rows are labelled with percentiles of the monetary policy indicator $(\Delta M)$ and GDP growth $(\Delta G D P) . B$ quartiles are calculated from bankquarters entering the regressions reported in Table 5. Effects are averaged over the three financial uncertainty proxies. 